BULLETIN Bulletin hispanique

HISPANIQUE Université Michel de Montaigne Bordeaux

$120-2$ | 2018

Varia

\title{
La elegía de Cernuda a Lorca en su tradición: notas para un estudio de las fuentes de $A$ un poeta muerto (F.G.L.)
}

L'élégie de Cernuda à Lorca dans sa tradition : notes pour une étude des sources de A un poeta muerto (F.G.L.)

Cernuda's elegy to Lorca in its tradition: notes for a study of the sources of "A un poeta muerto (F.G.L)"

\section{Adalid Nievas Rojas}

\section{CpenEdition}

\section{Journals}

Edición electrónica

URL: https://journals.openedition.org/bulletinhispanique/6643

DOI: 10.4000/bulletinhispanique.6643

ISSN: $1775-3821$

Editor

Presses universitaires de Bordeaux

Edición impresa

Fecha de publicación: 10 diciembre 2018

Paginación: 505-528

ISBN: 979-10-300-0337-6

ISSN: 0007-4640

\section{Referencia electrónica}

Adalid Nievas Rojas, «La elegía de Cernuda a Lorca en su tradición: notas para un estudio de las

fuentes de $A$ un poeta muerto (F.G.L.)», Bulletin hispanique [En línea], 120-2 | 2018, Publicado el 02 enero 2022, consultado el 08 enero 2022. URL: http://journals.openedition.org/bulletinhispanique/6643 ;

DOI: https://doi.org/10.4000/bulletinhispanique.6643 


\title{
La elegía de Cernuda a Lorca en su tradición: notas para un estudio de las fuentes de $A$ un poeta muerto (F.G.L.)
}

\author{
Adalid Nievas Rojas \\ Universitat de Girona
}

Lélégie de Cernuda à Lorca dans sa tradition : notes pour une étude des sources de A un poeta muerto (F.G.L.)

Cet article montre que les modèles pris en compte par Cernuda, dans son élégie à la mort de Lorca, sont ceux qui ont fixé la tradition de l'élégie pastorale «de l'amitié». En conséquence, les échos de la poésie de Garcilaso, présents dans $A$ un poeta muerto (F.G.L.), doivent être mis en relation avec une filiation littéraire élargie.

Mots-clés: Luis Cernuda, Federico García Lorca, Garcilaso, élégie pastorale.

En el presente artículo se demuestra que los modelos que Cernuda tuvo en cuenta en su elegía escrita por la muerte de Lorca son los mismos que han conformado la elegía pastoral «de la amistad». Los ecos de la poesía de Garcilaso presentes en $A$ un poeta muerto (F.G.L.) deben ponerse, por tanto, en relación con ese alcance literario más amplio.

Palabras clave: Luis Cernuda, Federico García Lorca, Garcilaso, elegía pastoral.

Cernuda's elegy to Lorca in its tradition: notes for a study of the sources of "A un poeta muerto (F.G.L)"

This article demonstrates that the models Cernuda took into account when writing his elegy after Lorca's death are those that established the tradition of the pastoral elegy "of friendship". The echoes of Garcilaso's poetry presented in "A un poeta muerto (F.G.L.)” must therefore be connected with that broader literary relation.

Keywords: Luis Cernuda, Federico García Lorca, Garcilaso, pastoral elegy. 
E xtrańa comprobar que el justo prestigio de la elegía compuesta por Luis Cernuda con motivo de la muerte de Federico García Lorca en 1937 no haya tenido un correlato crítico más amplio del que se aprecia en la por otra parte cuantiosa bibliografía sobre la obra del poeta sevillano ${ }^{1}$. Es de notar, además, que la sólida adhesión que presenta la elegía a unas circunstancias vitales e históricas muy concretas (el asesinato de un poeta y ser querido para el autor, además de la guerra civil espańola como trasfondo) ha dado lugar a que la exégesis del texto se fundamente siempre sobre los mismos ejes conceptuales, a saber: el vate como trasunto terreno de lo divino, como criatura que la sociedad no comprende y rechaza; su poder creador frente a la fuerza destructiva de un pueblo cainita, y la muerte entendida como destino, liberación y consuelo, resuelta en términos positivos por ser puente hacia la trascendencia del amor anhelado $^{2}$. Estas románticas aproximaciones, aunque acertadas e ineludibles en el estudio de la trayectoria del pensamiento poético y de la actitud ética cernudianos, parece que solo perciban en el texto la expresión de una ontología del poeta a partir de la aplicación y sistematización de los principios de un solo bloque filosófico, esencialmente idealista. Un asedio interpretativo así pone de manifiesto cierto carácter tautológico por su insistencia en una única lectura, incapaz de cerrar el círculo hermenéutico al poner en olvido la tradición literaria que orienta el texto y vertebra sus fuentes.

1. La presente publicación se inscribe en el proyecto «Garcilaso de la Vega en Italia. Estancia en Nápoles» (2016-2019): FFI2015-65093-P.

2. El estudio más completo sobre «A un poeta muerto (F.G.L.)» sigue siendo hoy el de Derek Harris, «Una versión primitiva de la elegía de Luis Cernuda por la muerte de Lorca», en El escritor y la crítica, ed. de Derek Harris, Madrid, Taurus, 1977, pp. 286-302. Casi toda la investigación posterior que aborda algún aspecto del poema de Cernuda parte de este artículo de Harris o sigue las consideraciones que al respecto había apuntado el crítico inglés en su libro anterior, Luis Cernuda: A study of the poetry, Londres, Tamesis, 1973, pp. 77-78, 80 y 104-109. Véase, por ejemplo: C. Christopher Soufas, Jr., «Cernuda and daimonic power», en Hispania, vol. 66, n. ${ }^{\circ}$ 2, 1983, p. 174; Salvatore J. Poeta, «El proceso del luto y el proceso elegíaco en las tres versiones de "A un poeta muerto" de Luis Cernuda", en Actas del IX Congreso de la Asociación Internacional de Hispanistas 18-23 agosto 1986, Berlín, Frankfurt am Main, Vervuet, 1989, pp. 191-199; Ignacio Arellano, «El poeta como paria social en Cernuda. Glosas al poema "Góngora"”, en Revista Signos: Estudios de Lengua y Literatura, vol. XXX, n.o 41-42, 1997, pp. 11-12; Neil C. McKinlay, The poetry of Luis Cernuda: order in a world of chaos, Londres, Tamesis, 1999, pp. 126-136; Javier Pérez Bazo, «Cernuda ante la muerte y la victoria de García Lorca», en Federico García Lorca et Cetera, Leuven, Universitaire Pers Leuven, 2003, pp. 183196; Alfredo López-Pasarín Basabe, en "La muerte de Lorca y los poetas de "Hora de España" ", Journal of Liberal Arts n. ${ }^{\circ}$ 124, 2008, pp. 147-155. Mención aparte merecen los comentarios (por ser ligeramente anteriores a los de Derek Harris) que a propósito de la elegía escribió Philip Silver en su clásico estudio Et in Arcadia ego: a study of the poetry of Luis Cernuda. En realidad, los apuntes de Silver constituyen unas brevísimas notas (de enorme y lógica influencia en la crítica posterior, y coincidentes en buena medida con las que más tarde desarrollará Harris) centradas sobre todo en la idea de la búsqueda del amor eterno por parte de Cernuda. Aun así, hay que reconocerle a Silver el mérito de haber relacionado, aunque solo fuera de pasada, la elegía escrita por la muerte de Lorca con el poema «El joven marino» y con el importante cierre de «El éxtasis» (puede consultarse la versión española del estudio de Silver, Luis Cernuda: el poeta en su leyenda, Madrid, Alfaguara, 1972, pp. 145-147 y 157-158). 
Tan solo existe, que sepamos, un trabajo sobre el poema de Cernuda por la muerte de Lorca que haya tomado esa dirección investigadora: el de Miguel García-Posada, titulado bienintencionadamente "Cernuda y Garcilaso. Ecos garcilasianos en la elegía "A un poeta muerto (F.G.L.)" " ". La nota, que ha pasado sin pena ni gloria ante los ojos de la crítica ${ }^{4}$, podría estimarse en exceso breve, exigua de todo punto, ya que su celo comparatista se circunscribe a las dos últimas estrofas de la elegía, y las deudas atisbadas en la formulación textual de las mismas, aun considerándose "profundas, de espíritu y de visión ${ }^{5}$, acaban por atribuirse a efectos de una lectura aislada o particular (Garcilaso) y no a una asimilación cumulativa y de conjunto de una tradición determinada $a^{6}$. No obstante, es preciso subrayar el carácter pionero del artículo de García-Posada por lo que respecta a la búsqueda e identificación de fuentes y referencias a autores clásicos en la elegía, y su capacidad para generar un debate de alcance literario más amplio en ese mismo sentido indagatorio, que es por el que se encauza la presente investigación. Creemos que para remendar el corte sincrónico que supone la simple detección de los ecos garcilasianos resulta insoslayable percibir hasta donde sea posible sus enormes resonancias; ver la reminiscencia de la fuente y a ambas como eslabones de una tradición profundamente orgánica que se remonta a la Antigüedad, se cultiva en el siglo XVI y pervive en época romántica, y cuyos modelos, si no ejercieron un influjo directo sobre el poema de Cernuda, sí debieron de tener un papel preponderante en la ideación poética del fenómeno elegíaco que llevaría a cabo el poeta sevillano tras la muerte de su amigo Federico.

Tracemos un relato coherente sobre estas cuestiones partiendo del único punto de intertextualidad hasta ahora seńalado, esto es, las estrofas que sirven de cierre a la elegía, y que rezan así:

3. Miguel García-Posada, «Cernuda y Garcilaso. Ecos garcilasianos en la elegía "A un poeta muerto (F.G.L.)"”, Ínsula. Revista de Letras y Ciencias Humanas, n.o 455, 1984, pp. 1 y 3.

4. El artículo de García-Posada no aparece citado prácticamente en ningún sitio de la amplísima bibliografía sobre Cernuda. Una notable excepción es el estudio de José Miguel Serrano de la Torre, Antiguos y modernos en la poética de Luis Cernuda, Málaga, Universidad de Málaga, 2002. El autor intenta filiar el locus amoenus dibujado al final del poema cernudiano con el que ofrecen algunas liras del Cántico de San Juan de la Cruz (p. 225). Luis Gómez Canseco mencionó muy de paso el «recuerdo» de Garcilaso en los versos finales de «A un poeta muerto (F.G.L.)» sin citar la publicación de García-Posada; véase «Lo mitológico en Cernuda después de Invocaciones», en Las formas del mito en las literaturas hispánicas del siglo XX, ed. de Luis Gómez Canseco, Huelva, Universidad de Huelva, 1994, p. 118. Pocos años después, Gómez Canseco publicaba otro artículo sobre el poeta sevillano centrado en la influencia de la Égloga I de Garcilaso en la obra poética cernudiana; y, de nuevo, se hacía sin citar a García-Posada; véase «La visión del amado en el trasmundo: Luis Cernuda lee la Égloga I de Garcilaso», en Archivo Hispalense. Revista Histórica, Literaria y Artística, t. 81, n. ${ }^{\circ}$ 247, 1998, p. 86.

5. Miguel García-Posada, op. cit., p. 1.

6. Reelaboramos adrede las palabras que utiliza el propio Cernuda para explicar la influencia de la literatura inglesa en su poesía, en Luis Cernuda, Prosa I, vol. II, ed. de Derek Harris y Luis Maristany, Madrid, Siruela, 2002, p. 647. 


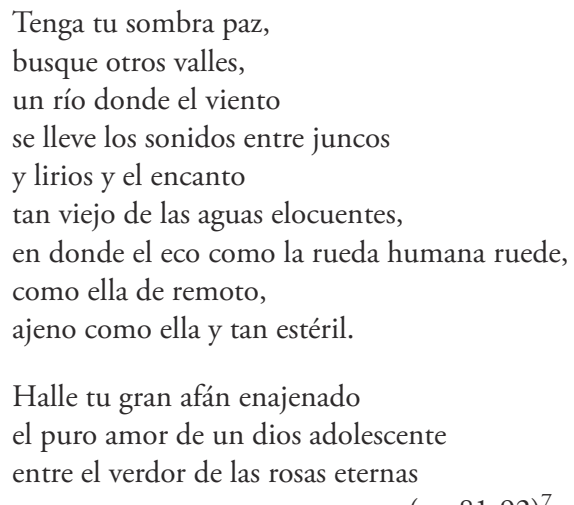

Nadie dudará de que esta delicadísima descripción del espacio que el poeta desea para la sombra de su amigo muerto dibuja un más allá configurado a través de la naturaleza, "un locus amoenus paradisíaco" ${ }^{8}$ que, como puso en claro García-Posada, Cernuda ha tomado intencionadamente de la Égloga I de Garcilaso. Reproduzcamos el pasaje en cuestión en su contexto inmediato?:

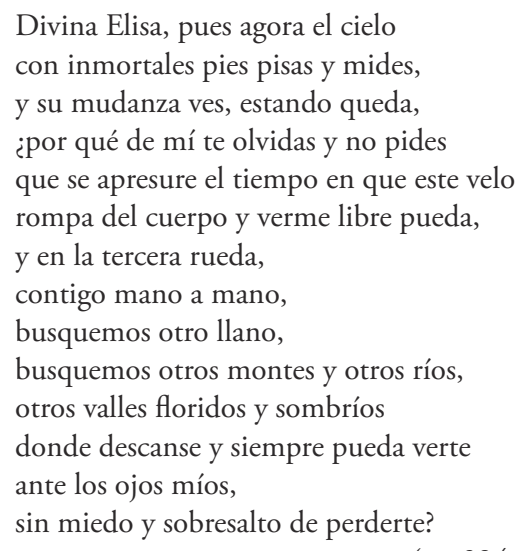

(vv. 394-407) $)^{10}$.

Recordemos, antes de nada, que fue el propio Cernuda quien facilitó que se estableciera la filiación garcilasiana al contestar por carta a Philip Silver la pregunta que el crítico le había formulado a propósito de su poema «El éxtasis» (1946), del libro Vivir sin estar viviendo, cuya estrofa final («E iremos por el prado a las aguas, donde olvido, / sin gesto el gozo, muda la palabra, / vendrá

7. Citamos siempre a Cernuda por la edición canónica de Derek Harris y Luis Maristany: Luis Cernuda, Poesía completa, vol. I, Madrid, Siruela, 2005. El texto íntegro de «A un poeta muerto (F.G.L.)» se encuentra en pp. 254-258.

8. Miguel García-Posada, op. cit., p. 3.

9. Para las posteriores consideraciones, remito a mi trabajo académico Cernuda, tras los clásicos ingleses y españoles. Metafísica, mistica y meditación en la poesia de la etapa inglesa (2014), en línea: https://dugi-doc.udg.edu/handle/10256/9558.

10. Garcilaso de la Vega, Obra poética y textos en prosa, ed. de Bienvenido Morros, Barcelona, Crítica, 2007, p. 218. Citamos siempre a Garcilaso por esta edición. 
desde tu labio hasta mi labio, / fundirá en una sombra nuestras sombras») coincide en sentido y visión (y por tanto también en reminiscencia) con la penúltima de "A un poeta muerto (F.G.L.)»" Escribe Cernuda: “"El éxtasis" (el título viene de The Extasie, de Donne) es ejemplo flagrante de whishful thinking: muerte y resurrección [...]. La reunión y el paraje de la misma recuerdan deliberadamente el final de una égloga de Garcilaso: "Busquemos otros montes y otros ríos, / otros valles floridos y sombríos”, etc.» ${ }^{12}$. Así es, tanto en los versos de Cernuda como en los de Garcilaso se aprecia el mismo afán neoplatónico de trascender los límites físicos mediante la construcción de un espacio que, pese a estar definido por la alteridad, remite a un ámbito pagano en el que tiene lugar la resurrección de los que han muerto. Todo parece apuntar a que este mundo de los bienaventurados le llega a Cernuda merced a Garcilaso; esto no solo lo sugiere el rotundo testimonio de la carta citada, sino también el tipo de asimilación que hizo el sevillano de los versos de nuestro gran clásico: «En ella [en la obra de Garcilaso] aparece la vida con la serenidad de lo contemplado desde el otro lado de la muerte»; o: "En sus versos, atemperando la gracia y voluptuosidad mundana, sentimos siempre, visible o invisible, la presencia de la muerte» ${ }^{13}$. Está claro que esta dimensión, podríamos decir, trascendente, más próxima a las formas sobrehumanas e intelectivas que a las relacionadas con el sensus communis, que aloja la poesía de Garcilaso, satisface las necesidades animistas y literarias de Cernuda al hallar este un modelo cercano (es decir, en su propia lengua) en el que basarse para la materialización verbal del sentimiento elegíaco transmutado en esperanza. Pero la realidad evidencia, sin embargo, un fondo más hondo de dependencias genéticas y de implicaciones literarias: la deliberada alineación cernudiana con la literatura grecolatina y, más concretamente, con sus realizaciones bucólicoelegíacas.

Es muy probable que Cernuda leyera a Garcilaso a la luz de los autores gentiles. Entre las obras que pertenecieron al poeta sevillano, conservadas en los fondos documentales de la Residencia de Estudiantes, encontramos, por ejemplo, dos libros de Virgilio, Les cuvres de Virgile: traduites en françois (1801) y Las Bucólicas de Virgilio traducidas en versos castellanos (1829). Hay

11. Cernuda omite por completo otra fuente clarísima del final de «El éxtasis»: Charles Baudelaire. Leemos en la tercera y cuarta estrofa de «Le Léthé»: «Dans un sommeil aussi doux que la mort, / j'étalerai mes baisers sans remords / sur ton beau corps poli comme le cuivre. / Pour engloutir mes sanglots apaisés / rien ne me vaut l'abîme de ta couche; l'oubli puissant habite sur ta bouche, / et le Léthé coule dans tes baisers»; véase Charles Baudelaire, Obra poética completa, ed. bilingüe de Enrique López Castellón, Madrid, Akal, 2003, pp. 90-91.

12. La carta es del 21 de febrero de 1961. Véase Luis Cernuda, Epistolario (1924-1963), ed. de James Valender, Madrid, Publicaciones de la Residencia de Estudiantes, 2003, p. 906; pero también Silver, op. cit., p. 158. Naturalmente, García-Posada se refiere a la carta para apuntalar el "préstamo garcilasiano» de la elegía, en op. cit., p. 3; y también Gómez Canseco, en «La visión del amado...», op. cit., p. 87. Para un excelente análisis de «El éxtasis», véase el estudio de Julián Jiménez Heffernan, La palabra emplazada. Meditación y contemplación de Herbert a Valente, Córdoba, Universidad de Córdoba, 1998, pp. 277-283.

13. Luis Cernuda, Prosa I, op. cit., pp. 490-491. 
que llamar la atención sobre este último debido a la aclaración en nota que a propósito del canto de Menalcas en la Égloga $V$ escribe Félix M. ${ }^{a}$ Hidalgo, traductor y comentarista de la obra: «Ergo alacris silvas... [...]. Garcilaso imitó este pasaje y el anterior en su égloga primera ${ }^{14}$. Seguidamente, Hidalgo cita la célebre invocación del canto fúnebre de Nemoroso ( Divina Elisa, pues agora el cielo...»). La observación, naturalmente, no era producto de la sagacidad del editor, pues hacía más de dos siglos que el pasaje garcilasiano había sido esclarecido por Fernando de Herrera en sus Anotaciones: «aunque esta estança tenga imitación de Virgilio...» ${ }^{15}$, de cuya primera edición, por cierto, adquirió Cernuda un ejemplar en enero de $1936^{16}$, tan solo diez u once meses antes de que diera comienzo a la composición de su elegía. Sea como fuere, lo cierto es que bien convencido debía estar Hidalgo de la filiación apuntada, ya que tradujo las primeras notas del panegírico de Menalcas apoyándose en la estructura garcilasiana:

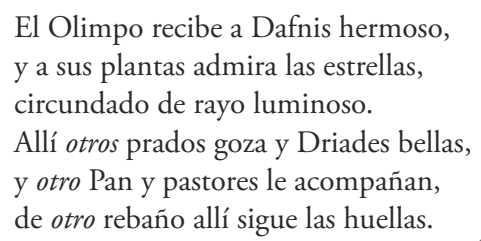

En vista de tales evidencias, se impone el supuesto de que Cernuda acudió a la fuente de Garcilaso con la idea, bastante ajustada a la realidad, por otra parte, de que el modelo del poeta toledano en la configuración de los Campos Elíseos era Virgilio, lo cual significa que, en cierto modo, esa parte de su tradición Cernuda debió percibirla como un eco -feliz continuidad- de la tradición clásica ${ }^{18}$. O dicho de otra manera quizá más exacta: seguir a Garcilaso en la visión del trasmundo era, en efecto, seguir a Virgilio, pero sobre todo, era también participar en la fecunda tradición de la elegía pastoral, que hunde sus raíces en el primero de los idilios teocritianos, y cuyo núcleo es la querimonia o lamento por la muerte de un protopastor, de un personaje mítico o de un

14. Virgilio, Las Bucólicas de Virgilio traducidas en versos castellanos, con notas y observaciones críticas por Félix M. ${ }^{a}$ Hidalgo, Sevilla, Imprenta de H. Dávila, Llera y Compañía, 1829, pp. 139-140.

15. Fernando de Herrera, Obras de Garcilasso de la Vega con anotaciones de Fernando de Herrera, Sevilla, por Alonso de la Barrera, 1580, p. 444.

16. Lo afirma Antonio Rivero Taravillo, en Luis Cernuda. Años españoles (1902-1938), Barcelona, Tusquets, 2008, p. 326. Es de notar que Cernuda recurre a menudo a la obra de Herrera (Luis Cernuda, Prosa I, op. cit., pp. 73 y 489).

17. Virgilio, op. cit., p. 127. (La cursiva es nuestra).

18. No parece tener otro sentido la siguiente asociación del propio Cernuda, hecha, precisamente, en su estudio al toledano: "Cambian las modas literarias, pero la poesía de Garcilaso, como la de Teócrito, la de Virgilio, aparece hoy tan fresca y tan bella como ayer, como acaso ha de parecer siempre», en Luis Cernuda, Prosa I, op. cit., p. 492. 
poeta $^{19}$. La razón de este acercamiento es algo que nos parece necesariamente implícito en unas palabras, más reveladoras ahora que nunca, que el propio Cernuda dejó escritas en un texto sobre Lorca, cuando no hacía ni cuatro meses que había finalizado la versión definitiva de su elegía:

No he indicado, en unos versos que a su memoria dediqué, ciertos fuertes trazos realistas, como el pelotón de la guardia civil que lo mató, omisión que algunos echaron de menos, olvidando que no quería cantar su muerte, sino cantar su resurrección ${ }^{20}$.

La aclaración de Cernuda podrá parafrasearse de varias formas y desde diversos campos de conocimiento y doctrina, pero, en esencia, desvela que todo en la elegía se encamina hacia su final consolatorio, esto es, hacia la idea de la supervivencia post-mortem del fallecido, su apotheosis. No cabe la menor duda de que esta consolatio sitúa el poema de Cernuda en la estela de la elegía de carácter funerario; ahora bien, la propuesta paradisíaca, sensual y paganizante de su formulación implica la necesaria orientación del texto cernudiano hacia expresiones de bucolismo de ciertas elegías, o, si se prefiere, hacia expresiones elegíacas de algunas églogas ${ }^{21}$. Cernuda sabía muy bien que el hilo temático de la apotheosis de Elisa en la Égloga I se remontaba al Idilio I de Teócrito con la apotheosis de Dafnis ${ }^{22}$; sabía, además, que Bion de Esmirna había cantado por la muerte de Adonis, que el Pseudo-Mosco había cantado por la muerte de $B_{i o n}^{23}$; sabía que Virgilio había recreado magistralmente

19. Para una aproximación a esta modalidad literaria es fundamental el estudio de Juan Montero, «Sobre las relaciones entre la elegía y la égloga en la poesía del s. XVI», en La elegía, ed. dirigida por Begoña López Bueno (Grupo P.A.S.O.), Sevilla, Universidad de Sevilla, 1996, pp. 215-225.

20. Luis Cernuda, Prosa II, vol. III, ed. de Derek Harris y Luis Maristany, Madrid, Siruela, 2002, p. 130.

21. El interés de Cernuda por la contaminación entre los dos polos de lo bucólico y lo elegíaco se manifiesta desde su juventud, y no se circunscribe al ámbito literario. En una carta a Higinio Capote, del 17 de enero de 1926, Cernuda escribe: «He ido varias veces al Prado; esta mañana estaba invadido por una turba que dejaba desierta la sala de Poussin, donde me detuve bastante», en Luis Cernuda, Epistolario (1924-1963), op. cit., pp. 18-19. Como es sabido, la pintura bucólica de Poussin se hace eco del memento mori latino (piénsese, sin ir más lejos, en su celebérrimo cuadro Los pastores de Arcadia, más conocido como Et in Arcadia ego).

22. En Historial de un libro, Cernuda reconoce que, «desgraciadamente, no tengo conocimiento de la lengua griega»; aun así, admitirá: «Teócrito y Virgilio siempre fueron para mí poetas predilectos», en Luis Cernuda, Prosa I, op. cit., pp. 628 y 652. La afición por Teócrito es sin duda temprana. En El indolente (relato compuesto en 1929), el protagonista recuerda la vez en que encontró unos libros que un viajero alemán había dejado olvidados: «Entre otros hallé un tomo de Teócrito, que yo conocía", en Luis Cernuda, Prosa II, op. cit., p. 288.

23. Que Cernuda conocía estas obras lo sabemos por su estudio a Algernon Charles Swinburne, cuya elegía titulada Ave atque Vale (escrita con ocasión de la muerte de Baudelaire) le suscita este comentario: «En dicho poema sigue la pauta del "Lamento por Bion", de Mosco, con atmósfera y tono clásicos y paganos», en Luis Cernuda, Prosa I, op. cit., p. 434. Cernuda pudo leerlas por primera vez (igual que los idilios de Teócrito) en la traduccón castellana de José Antonio Conde (Madrid, 1796) o en la más difundida de Ignacio Montes de Oca (Madrid, 1880). Es posible, además, que leyera el Idilio de Bion a la muerte de Adonis que tradujo Marcelino MenéndezPelayo, en Estudios poéticos, Madrid, Imprenta Central a cargo de Víctor Saiz, 1878, pp. 25-30. 
en su Bucólica $V$ aquellas muestras de poesía bucólico-elegíaca griega, y que tiempo más tarde, ya en lengua vernácula y en distintas épocas, hombres como Iacobo Sannazaro, John Milton o Percy Bisshe Shelley habían contribuido con su particular reelaboración a la reviviscencia de esa modalidad literaria ${ }^{24}$. Una tradición en la que, como adelantábamos más arriba, se lamenta la muerte de un protopastor, de un personaje mítico o de un poeta para luego celebrar su apotheosis debió serle grata a alguien como Cernuda, cuyo propósito no solo consistía en cantar la resurreción de su amigo, sino cantar la resurreción de un poeta muerto, como él mismo explicitó en el título de su elegía. No puede dejarse de advertir, además, que dicha tradición orbita siempre, aunque en diferentes niveles, alrededor del homoerotismo, pues, al fin y al cabo, de lo que se trata es del llanto enardecido de un hombre por la muerte de otro hombre, generalemente joven, al que se atribuye también el don poético ${ }^{25}$. Cernuda, fidelísimo como pocos a sí mismo y, por tanto, a su naturaleza homosexual, no pudo sino sentirse atraído por esta tradición de elegías pastorales ante la muerte de un amigo como Lorca, a quien, según el sevillano, «algo que yo apenas conocía o que no quería reconocer comenzó a unir[me] por encima de aquella presentación un poco teatral, a través de la cual se adivinaba el verdadero Federico García Lorca elemental y apasionado» ${ }^{26}$. Es cierto que no encontraremos en la elegía de Cernuda indicios de una reescritura basada en los más rígidos principios de la imitatio. El poema no es una égloga fúnebre, ni el poeta concibe las múltiples realizaciones de la cultura greco-pagana como formas meramente decorativas ${ }^{27}$. De las principales convenciones de ese género de poesías a que venimos aludiendo, tan solo la apotheosis (razón última de la elegía) presenta unas concomitancias indubitables respecto a los diferentes

24. Más adelante trataremos sobre Milton y Shelley. De Sannazaro baste con señalar estos versos de la canción que Ergasto entona sobre la sepultura de Androgeo, en la égloga V de la Arcadia: "Alma beata e bella, / che da' legami sciolta / nuda salisti nei superni chiostri, / ove con la tua stella / ti godi inseme accolta / e lieta ivi, schernendo y pensier nostri, / quasi un bel sol ti mostri / tra li piú chiari spiriti, / e coi vestigi santi / calchi le stelle erranti; / e tra pure fontane e sacri mirti / pasci celesti greggi, / e i tuoi cari pastori indi corrggi; altri monti, altri piani, / altri boschetti e rivi / vedi nel cielo, e piú novelli fiori» (vv. 1-16), en Iacobo Sannazaro, Arcadia, ed. de Francesco Erspamer, Milán, Mursia, 1990, pp. 102-103 (la cursiva es nuestra).

25. Véase el capítulo que Greogry Woods dedica a los elegíacos pastoriles en su imprescindible Historia de la literatura gay. La tradición masculina, trad. de Julio Rodríguez Puértolas, Madrid, Ediciones Akal, 2001, pp. 119-134.

26. Cernuda se refiere, obviamente, a la homosexualidad de ambos como base de aquella incipiente amistad; véase Luis Cernuda, Prosa II, op. cit., p. 149. Así lo interpreta también Ian Gibson al valorar el recuerdo de Cernuda, en Vida, pasión y muerte de Federico García Lorca, Barcelona, Plaza y Janés, 1998, p. 305.

27. Muy inteligente es en ese sentido la observación de Derek Harris: «Es curioso que los dioses antiguos tengan tan limitada presencia física en la obra de Cernuda [...]. Esta minimalización de la presencia, aunque no del espíritu de lo que presentan los dioses, se debe, seguramente en parte, a la necesidad de esquivar el helenismo barato del modernismo", en Luis Cernuda, Poesía completa, op. cit., p. 73. 
modelos ${ }^{28}$. En «A un poeta muerto (F.G.L.)», la lamentatio no es fruto de una naturaleza que participa del duelo, ni se suman a ella las deidades silvestres. Las referencias mitológicas se mitigan, y varios tópicos se reformulan (tal ocurre con el de la mors inmatura o el de la flor tronchada) o desaparecen en la versión definitiva tras su leve insinuación en los primeros estadios redaccionales (el recuerdo, por ejemplo, de los amigos en dulce compañía bajo la sombra amena de los árboles $\left.{ }^{29}\right)$. Y, pese a todo, Cernuda reelabora un poema de cuño propio inspirado, en gran parte, en la tradición bucólico-elegíaca, a la que llegó, como se verá a continuación, de forma directa y por diversas vías.

Cernuda debió de tener su primera toma de contacto con todo ese material poético a raíz de la lectura de Virgilio en la edición de Félix M. ${ }^{a}$ Hidalgo (1829), quien explicaba lo siguiente a propósito de la resurrección de Dafnis en la Bucólica $V$ :

Todo el mundo conoce la apoteosis de Adonis por Bion; pero este no tiene ni la gracia de Teócrito, ni el gusto esquisito de Virgilio; y se conoce bien que su idilio es una elegía pastoral para las fiestas de Venus [...].

Milton en su égloga titulada Lícidas ha quedado muy atrás de Teócrito y de Virgilio. La parte elegíaca es muy larga y distante de la sencillez pastoril. Con motivo de la muerte del pastor establece el poeta una distinción filosófica entre la verdadera y falsa gloria [...]. En el apoteosis de Lícidas compara Milton su héroe, levantándose de la muerte y encaminándose al olimpo, al sol que se sumerge en el océano para volver a ascender sobre el horizonte. Uno de los cuadros más felices de Virgilio es aquel en que representa la admiración de Dafnis arribando al olimpo; pero en la égloga de Milton no es Lícidas el que se admira, es el olimpo, que se sobrecoje de sorpresa, viendo entrar en su recinto un pastor semejante al sol ${ }^{30}$.

Dejando a un lado su carácter manifiestamente preceptista, lo que interesa destacar del comentario es, en primer lugar, su remisión a unas obras que el propio Hidalgo se encarga de incluir en la tradición de lo que él mismo

28. Véase el compendio de George Norlin, en "The conventions of the pastoral elegy», The American Journal of Philology, vol. 32, n. ${ }^{\circ} 3$, 1911, pp. 294-312; y la clásica antología de Thomas Perrin Harrison, The pastoral elegy. An anthology, Nueva York, Octagon Books, 1968 (especialmente la «Introduction», pp. 1-24).

29. En la primera redacción de la elegía Cernuda imaginó este paisaje: «Pensé la vida como una tranquila velada / junto a la grata lámpara / como una sonriente mańana / en el campo impasible / bajo los brazos eternos de los chopos y pinos / vivo olvidado y sereno en la naturaleza / como una breve estrella en el cielo desmedido». Después, en una versión posterior, pero anterior a la definitiva, volvió sobre esa bucólica estampa en la que no podía faltar la compañía de su amigo: «Brillaba el mundo con fulgor tranquilo / y creímos que los ojos del día / no verían otra vida / sino ésta del claro pensamiento, / el cuerpo olvidado en la naturaleza, / entre el abrazo eterno de los árboles, / como una breve estrella por el cielo impasible» (vv. 14-20), en Derek Harris, El escritor y la crítica, op. cit., pp. 287 y 291. Recordar la vida tranquila y dichosa en la naturaleza en compañía del amigo muerto es frecuente en la elegía pastoral. Es posible que Cernuda tuviera en mente unos versos del Lycidas de Milton (que ya había leído en 1937, como se demostrará a continuación) donde se recrea una escena parecida: «Together both, ere the high lawns appeared / under the opening eyelids of the Morn» (vv. 25-26), en Thomas Perrin Harrison, op. cit., p. 203.

30. Virgilio, op. cit., pp. 146-147. 
denomina la "elegía pastoral». Por tanto, a través de la edición de las Bucólicas que realizó el crítico gaditano, Cernuda pudo haber descubierto no solo la existencia de esa tradición, sino también a algunos de los principales autores que la conformaban, como Bion o Milton. Del poema de este último, además, la nota de Hidalgo refería datalles importantes, como el océano de connotaciones ultraterrenas, la identificación del sol con el fallecido o el tema de la gloria, imágenes que tal vez fueron el germen de ciertos planteamientos de la elegía cernudiana ${ }^{31}$.

Ocurriera así o no, hay que señalar que el poema Lycidas, la elegía pastoral que Milton escribió con motivo de la muerte de su amigo Edward King (1637), pudo motivar igualmente el acercamiento de Cernuda a la poesía bucólicoelegíaca, e incluso tener un papel relevantísimo en su consideración de la Égloga I de Garcilaso como contribución de la más alta tradición española a esta tradición de bucolismo y elegía de origen teócrito-virgiliano. Gracias a la correspondencia entre Cernuda y Salvador de Madariaga, rescatada del olvido hace apenas algunos años, sabemos que el poeta sevillano leyó Lycidas en traducción del propio Madariaga:

Las traducciones son un tour de force. La de Lycidas es bellísima. Y por cierto que hallo a veces en ellas algo que usted me reprochaba: «Nunca decir tu amor quieras». Como usted ve, ordenar las palabras poéticamente dentro del verso es una cosa, y acomodarse al orden acostumbrado en el lenguaje diario es otra. Por cierto que yo también tengo una traducción del Never seek to tell thy love, aunque nunca publicada ${ }^{32}$.

Poco debe importarnos que la carta sea de 1942. Por un lado, la relación de Cernuda con Madariaga se puede datar sin problema en 1928, cuando el escritor gallego animaba a nuestro poeta a que estudiara la lengua inglesa ${ }^{33}$. Por otro lado, el poema de William Blake al que pertenece el verso que se cita en la carta Cernuda debió de leerlo o bien en el libro Ensayos anglo-españoles ${ }^{34}$, de 1922, o bien en el Manojo de poesías inglesas ${ }^{35}$, de 1919, ambos de Salvador de Madariaga. En cualquier caso, la traducción del poema de Milton Cernuda solo pudo haberla leído en este último libro, el único lugar donde había aparecido publicada hasta la fecha ${ }^{36}$. Esta antología, de tono claramente elegíaco, Cernuda debió leerla a todas luces no solo antes de 1942, sino también antes de 1937. Y si nos parece relevante señalarlo es porque en ella el poeta sevillano descubría,

31. Véanse los vv. 23-24, 53-59 y 87-89 de «A un poeta muerto (F.G.L.)».

32. Carta del 8 de diciembre de 1942. Se conserva en el Instituto José Cornide de Estudios Coruñeses, Fondo Documental Salvador de Madariaga, Caja 10. Esta y otras cartas de Cernuda a Madariaga están publicadas en la edición digital de El Cultural (1/11/2013): www.elcultural. com/revista/letras/Querido-don-Salvador/33556

33. "Madariaga me escribió dándome amplias promesas; me indicó que estudiara inglés», carta de Cernuda a Madariaga, 2 de noviembre de 1928, en Luis Cernuda, Epistolario (19241963), op. cit., p. 99.

34. Salvador de Madariaga, Ensayos anglo-españoles, Madrid, Publicaciones Atenea, 1922, pp. 134-135.

35. Salvador de Madariaga, Manojo de poesias inglesas, Cardiff, Williams Lewis, 1919, pp. 18-19.

36. Ibid., pp. 9-16. 
en efecto, una traducción de Lycidas, pero también una composición clave de la tradición bucólico-elegíaca que el traductor emparentaba con la Égloga I de Garcilaso:

El poema sigue una convención pastoral que recordará a los lectores españoles el estilo de Garcilaso, analogía sin duda debida al uso de modelos comunes, italianos o latinos. La Égloga I, verdadera doble elegía, es quizá la poesía española que más recuerda a Lycidas, no solo po-r su convención externa sino por su ternura y el delicado sentimiento de la naturaleza de que está impregnada ${ }^{37}$.

Al imaginar la apotheosis de Lorca, Cernuda describió un cielo de conscientes ecos garcilasianos, pero sabía sin duda que al hacerlo, también se dejaban oír los de Milton, ya en el inglés original («Where, other groves and other streams along» ${ }^{38}$ ), ya en el español de la traducción de Madariaga ( YYa goza de otro ejido, / de otras corrientes límpidas y hondas ${ }^{39}$ ).

Sería, sin embargo, otro libro de Madariaga el que acabaría desencadenando el más fructífero y determinante acercamiento de Cernuda al mundo de la elegía pastoral: su Shelley and Calderón and another essays on English and Spanish poetry, publicado en Londres en 1920. Es altamente probable que esta obra (la primera en traer de verdad a Shelley a la tradición poética española), sumada a la influencia directa de Madariaga, propiciara la temprana fascinación de Cernuda (y probablemente también la de Manuel Altolaguirre) por la obra de Percy Bysshe Shelley, autor del Adonais, una de las cumbres de la elegía pastoral inglesa, dedicada en 1821 a la muerte de John Keats ${ }^{40}$. Precisamente de este poema, Altolaguirre llevó a cabo la primera traducción española, primero de las 33 primeras estrofas, en 1935, para la revista bilingüe 1616, editada por él mismo junto con su esposa Concha Méndez durante su estancia en Londres ${ }^{41}$. $\mathrm{Al}$ año siguiente, en febrero de 1936, ya de vuelta en Madrid, Altolaguirre daba a las prensas de Viriato, 73 (su residencia, y también la de Cernuda, que vivía en el piso que había encima del que ocupaban los Altolaguirre) su traducción completa del Adonais ${ }^{42}$, una obra que, por supuesto, nuestro poeta conocía muy bien y desde hacía tiempo por hallarse incluida en la edición

\section{Ibid., p. 43.}

38. Lycidas, v. 174. Citamos a Milton por la antología de Harrison, op. cit., p. 207.

39. Salvador de Madariaga, Manojo de poesías inglesas, op. cit., p. 15.

40. En carta a Juan Guerrero, escrita el 23 de enero de 1928, Cernuda dice: «Yo sólo podría hacer la comparación de esa obra [se refiere a la de Juan Ramón Jiménez] con la de alguno de los poetas universales - ¿Dante, Goethe, Shelley?...- a que tácitamente alude»; y en carta a Edward Sarmiento, escrita el 10 de octubre de 1938, el sevillano reconce la profunda admiración que había sentido por Shelley en otro tiempo: «Lo que ahora releo en inglés son las comedias de Shakespeare, que son maravillosas para mí como nunca, en su propio idioma. Shelley, que yo admiraba mucho, ahora que lo comprendo mejor me interesa menos». El interés de Cernuda por el poeta inglés tuvo que ser desde luego considerable, pues en algún momento anterior a 1940 tradujo "por gusto, entre otras cosas, la Defence of poetry de Shelley»; véanse todas las citas, respectivamente, en Luis Cernuda, Epistolario (1924-1963), op. cit., pp. 72, 259 y 298.

41. Percy Bysshe Shelley, «Adonais», trad. de Manuel Altolaguirre, 1616, n. . 5-6-7, 1935.

42. Percy Bysshe Shelley, Adonais. Elegía a la muerte de John Keats, trad. de Manuel Altolaguirre, Madrid, Héroe, 1936. 
que poseía de los versos de Shelley ${ }^{43}$. Pero ahora, incorporada a su inmediatez circunstancial (la obra se imprimió, como quien dice, en su propia casa, y hasta es posible que participara en algún punto en la traducción ${ }^{44}$ ) y a su horizonte poético poshölderliniano, Cernuda pudo contemplarla de cerca en su inmensa tradición de elegías pastoriles, y percibirla como reminiscencia activa del sentido trágico y mítico de la literatura clásica. Tras la muerte de Lorca, Cernuda decidió recordar, a buen seguro, el destino de Adonis que había releído hacía apenas medio año, y el de tantos mancebos mitológicos igualmente vencidos, cuya derrota se convierte siempre en victoria apoteósica. Y esta quedó expresada en la elegía cernudiana en los términos que siguen:

Halle tu gran afán enajenado el puro amor de un dios adolescente entre el verdor de las rosas eternas

(vv. 90-93).

Quizá uno de los mayores aciertos de García-Posada en su artículo sobre "A un poeta muerto (F.G.L.)» fue señalar que la resurrección que propone Garcilaso tiene lugar en la "tercera rueda» (cielo o constelación consagrada a Venus), lo que llevó al crítico a relacionarla directamente con ese "puro amor de un dios adolescente», y a añadir: «El cambio, de Venus a Apolo, no atenta contra esa correspondencia. En ambos poemas, en definitiva, el amor se asocia a la plenitud de los espíritus en el otro mundo» ${ }^{45}$. Desde luego, es imposible no estar de acuerdo con la afirmación final; ahora bien, ¿por qué a Apolo? GarcíaPosada se limita a apuntar el cambio, sin más precisiones. Pero lo cierto es que todo indica que, en rigor, no existe tal cambio, o que de haberlo, sería mínimo, y producto solo de un seguimiento coherente de los modelos tomados: elegías en las que, como la de Shelley por la muerte de Keats, "one poet associating the death of another poet with the fabled death of Adonis» ${ }^{46}$. La referencia cernudiana al sentenciado amante de Venus se inspira, no hay duda, en el

43. Como era de esperar, entre los libros que pertenecieron a Cernuda (conservados en la Residencia de Estudiantes) encontramos The lyrical poems and translations of Percy Bysshe Shelley (1924), que incluye la elegía por la muerte de John Keats, y The dramatic poems of Percy Bysshe Shelley (1922).

44. El sevillano debió sentirse próximo a la traducción que hizo Altolaguirre del Adonais, pues años más tarde, para la edición póstuma de sus Poesías completas (1960), se atrevió a revisar y a corregir algunos detalles. En carta a Concha de Albornoz, escrita el 6 de abril de 1960, Cernuda dice: «El libro de Manolo Altolaguirre, ya compuesto, parece quedará terminado en mayo o en junio. No tienes ni idea [de] la jaqueca que dieron las traducciones de Shelley y Pushkin, con endecasílabos cojos ambas [...] etc., etc. Un ejemplo: en el Adonais hallé la palabra "anademas", y como, tratándose de Manolo siempre es necesario cerciorarse, hallé que tal palabra designa una manera de cinta o diadema que ceñía la cabeza del atleta; y él había dicho algo así como que los rizos espesos de Keats estaban llenos de "anademas". Es decir: con la cabeza llena de mońitos. Si lo llego a dejar pasar...", en Luis Cernuda, Epistolario (1924-1963), op. cit., p. 847.

45. Miguel García-Posada, op. cit., p. 3.

46. Harold Bloom, The visionary company. A reading of english romantic poetry, Ithaca, Cornell University Press, 1971, p. 343. 
poema de Shelley, lo cual es posible y conveniente demostrar a partir de esta importante concomitancia. Leemos en un lugar de la elegía de Cernuda:

La sal de nuestro mundo eras,

vivo estabas como un rayo de sol

[...].

La muerte se diría

más viva que la vida

porque tú estás con ella

(vv. 23-24 y 34-36).

Algo parecido leemos en el epígrafe griego, atribuido a Platón, con que se abre el Adonais de Shelley:

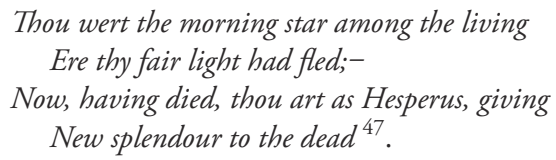

La coincidencia, como se ve, es doble: por un lado, Cernuda sigue a su modelo en lo que respecta a la imagen del poeta que iluminaba el mundo con su gracia resplandeciente ("aëreal eyes that kindle day»" ${ }^{48}$, dirá también Shelley, en la estrofa XIV). Por otro lado, también lo sigue al suponer que su amigo es nueva luz o nueva vida para la muerte (reformulación de la expresión de Shelley cuando escribe que "Death is dead, not he», en la estrofa XLI) ${ }^{49}$. No obstante, lo que nos interesa de verdad recalcar, a propósito del epígrafe platónico $^{50}$, es la coincidencia a la hora de situar al amigo muerto en la esfera

47. Seguimos la traducción inglesa del propio Shelley, titulada To stella, incluida en la edición que tuvo Cernuda. Véase Percy Bysshe Shelley, The lyrical poems and translations of Percy Bysshe Shelley, Londres Chatto and Windus, 1924, p. 402.

48. Todas los versos de la elegía por la muerte de John Keats se citan siempre por Percy Bysshe Shelley, Adonais, ed. bilingüe de Lorenzo Peraile, Madrid, Signos, 2008.

49. Esta idea de la luz asociada a la persona muerta, capaz de relumbrar en el trasmundo, ya se encuentra en Virgilio (Bucólica V, 56), y Milton (Lycidas, 166-172) la reelabora a través de esta comparación cósmica frecuentísima en la poesía grecolatina: «For Lycidas, your sorrow, is not dead, / sunk though he be beneath the watery floor. / So sinks the day-star in the ocean bed, / and yet anon repairs his drooping head, / and trinks his beams, / and with new-spangled ore / flames in the forehead of the morning sky: so Lycidas sunk low, but mounted high» (T. P. Harrison, op. cit., p. 207). Nótese que la consideración miltoniana del océano como espacio de trascendencia o resurreción metafísicas también se encuentra en «A un poeta muerto (F.G.L.)» (vv. 53-59).

50. El epigrama atribuido a Platón es el 670 del libro VII de la Antología griega, dedicado, como es sabido, a las composiciones de carácter funerario. Cernuda reconoce en Historial de un libro que, durante su estancia en París entre los meses de julio y septiembre de 1936, compró «la Antología griega, en texto griego y traducción francesa, editada en la colección Guillaume Budé. Menciono su adquisición porque esos breves poemas, en su concisión maravillosa y penetrante, fueron siempre estímulo y ejemplo para mí» (Luis Cernuda, Prosa I, op. cit., p. 642). El dato, más que relevante, sirve para entender el interés que pudo sentir Cernuda por el epigrama que usó Shelley; pero, al mismo tiempo, debe hacernos ver que Cernuda no leyó la breve composición de atribución platónica en la colección Guillaume Budé, ya que esta, en 1936, tan solo llevaba publicados los seis primeros libros de la Antología griega. De ahí que sospechemos 
de Venus, pues la comparación que establece Shelley entre el Keats fallecido y Véspero hace referencia, como bien indica Harold Bloom, a la constelación de la diosa del amor: "Keats has passed from the sphere of Lucifer, star of the morning, to that of Hesperus or Venus, first light of evening. This is a prefiguration of his fate within the poem ${ }^{51}$. Por esta causa, parece que Cernuda no alude a Apolo al escribir «halle tu gran afán enajenado / el puro amor de un dios adolescente / entre el verdor de las rosas eternas», sino a Adonis, el dios de la vegetación anual, muerto por Ares en figura de jabalí. De este modo, la relación entre la «tercera rueda» de Garcilaso y el «dios adolescente» de Cernuda queda mejor ajustada. Además, no debemos olvidar que, en la Égloga III, la muerte de Elisa se mitifica al ańadirse a las figuraciones que previamente tejen las ninfas en sus telas, entre las que se encuentra, también, la representación de la muerte de Adonis contemplada por Venus. En esta égloga, con no más de tres estrofas para el mito, se reelabora el prodigio de la transformación de la sangre de Adonis en rosa («las rosas blancas por allí sembradas / tornaban con su sangre coloradas $»^{52}$ ), cuya tradición se remonta, por lo menos, hasta el Canto fúnebre por Adonis, de Bion ("Tantas lágrimas vierte la diosa de Pafos, cuanta sangre vierte Adonis, y las dos se tornan flores en el suelo: de la sangre nace la rosa, de las lágrimas la anémona» ${ }^{53}$ ).

No cabe la menor duda de que, con la mención a las «eternas rosas», Cernuda está participando en esta tradición que vincula las rosas al mito de la muerte de Adonis. Parece claro que Garcilaso debió de tener en mente a Bion ${ }^{54}$, del mismo modo que también lo tuvo Shelley, cuya versión -como se echa de ver- no anda demasiado lejos de la atención de Cernuda. En la estrofa XXIV del Adonais, aparece Venus corriendo en busca de su amante herido, lastimándose la planta de los pies, cuya «sacred blood, like the young tears of May, / paved with eternal flowers that undeserving wayn. La proximidad de los elementos textuales («rosas eternas» / "eternal flowers») contribuye a demostrar que Cernuda está siguiendo muy de cerca el poema de Shelley, sin que ello implique en absoluto un distanciamiento por parte del sevillano de las fuentes clásicas del poeta inglés, como lo es el Canto fúnebre por Adonis ${ }^{55}$. De hecho, cuando Cernuda escribe que «la muerte se diría / más viva que la vida /

que el sevillano debió de conocer el poemita de marras por la traducción, ya citada, que hiciera Shelley, o quizá por una traducción francesa de toda la Antología griega anterior a la que recuerda en Historial de un libro, que pudo manejar en algún momento de su primer viaje a Francia, entre 1928 y 1929. Se trata de la Anthologie grecque, publicada en dos tomos por la Librairie de L. Hachette et Cie, en París, en 1863.

51. Harold Bloom, op. cit., p. 343.

52. Égloga III, vv. 183-184.

53. Canto fúnebre por Adonis, vv. 65-67; en Bucólicos griegos, ed. de Manuel García Teijeiro y M. ${ }^{\text {a }}$ Teresa Molinos Tejada, Madrid, Gredos, p. 333.

54. Lo explica Bienvenido Morros en su anotación a Garcilaso, en op. cit., p. 318-319.

55. Es preciso señalar que la edición que tenía Cernuda de las poesías de Shelley contiene también las traducciones que hiciera este de algunos fragmentos de los cantos fúnebres de Bion y el Pseudo-Mosco (los versos que relatan los prodigios de la sangre están, por supuesto, traducidos; véase Percy Bysshe Shelley, The lyrical poems..., op. cit., pp. 404-406. 
porque tú estás con ella», a lo que añade, "pasado el arco de su vasto imperio, / poblándola de pájaros y hojas / con tu gracia y tu juventud incomparables» (vv. 37-39), no deja de estar recordando el Adonis de Bion, quien dice claramente del joven mancebo que, «aunque muerto, es hermoso, hermoso en la muerte, cual si reposara " ${ }^{56}$. La misma idea, naturalmente, reaparecerá en unas líneas sobre Lorca que Cernuda escribirá a los tres o cuatro meses de haber terminado su elegía: "Allí donde él esté, sea sombra o memoria, está también lo más hermoso de la vida" ${ }^{57}$.

Las razones por las que Cernuda relacionó la muerte de Lorca con la figura de Adonis son varias y bien fáciles de poner en claro. La primera de ellas tiene que ver con el sentido antiguo que se le dio a las muertes de personajes mitológicos como Dafnis o el propio Adonis, un sentido que Harrison supo resumir perfectamente en la introducción de su antología de elegías pastorales:

The role of Nature, having its origin in man's grief for the death in Nature, reappears in the frequent contrast between the cyclic course of the seasons from death to life, on the one hand, and the finality of human death on the other ${ }^{58}$.

En ningún lugar como en «Los espinos» (1942) Cernuda ilustró mejor y más esclarecidamente su preocupación por ese mismo contraste. Reproduzcamos la composición entera aprovechando su brevedad con el fin de apuntalar con más firmeza nuestro principal asunto:

Verdor nuevo los espinos
tienen ya por la colina,
toda de púrpura y nieve
en el aire estremecida.
Cuántos ciclos florecidos
les has visto; aunque a la cita
ellos siempre serán fieles,
tú no lo serás un día.

56. Canto fúnebre por Adonis, v. 71; en Bucólicos griegos, op. cit., p. 334. Es posible, incluso, que otras manifiestaciones de poesía griega influyeran también en alguna de esas visiones cernudianas, como la de los pájaros que el fallecido trae consigo al pasar el arco mortal, evidente alusión al poeta como cantor, cuyos magníficos sones podrán ser escuchados en la muerte (igual que los de Orfeo). No es descabellado pensar, por ejemplo, que Cernuda pudo haber tenido en cuenta para esa imagen el siguiente epigrama de Calímaco, que habría leído en una edición parisina de la Antología griega (véase la nota 50): «Quelqu’un, ô Héraclite, m’a dit ton trépas et m'a plongé dans les larmes, et je me suis ressouvenu combien de fois tous les deux nous avions, au milieu de nos doux entretiens, enseveli le soleil; mais toi, cher hôte d'Halicarnasse, depuis longtemps, je ne sais où, tu n'es que cendre. Oh! du moins tes rossignols vivent, et sur eux, ravisseur de toutes choses, le dieu d'enfer ne portera pas la main» (A. P. VII, 80), en Anthologie grecque, tomo I, París, Librairie de L. Hachette et Cie, 1863, p. 139. La referencia a la «cendre» en absoluto es paradójica, y acaso se corresponda con «la sombra en que has caído» del poema cernudiano (v. 52).

57. Luis Cernuda, Prosa II, op. cit., p. 124.

58. Thomas Perrin Harrison, op. cit., p. 3. 
Antes que la sombra caiga, aprende cómo es la dicha ante los espinos blancos y rojos en flor. Ve. Mira ${ }^{59}$.

La serena aceptación de la caducidad humana, más patente si cabe en confrontación con el revivir perpetuo de la naturaleza, que se aprecia en el poema «Los espinos» no es sino amarga confirmación en la elegía escrita por la muerte de Lorca: "Aquí la primavera luce ahora [...]. / Igual todo prosigue, / como entonces, tan mágico, / que parece imposible / la sombra en que has caído» (vv. 40 y 49-52). Cernuda conocía sin duda que el topos del contraste entre el eterno renacer de la naturaleza y la muerte humana contaba con una larga tradición en la literatura occidental; pero ante la muerte prematura de Lorca, quiso recordar, primero, la bucólica lamentación que en ese mismo sentido había expresado el Pseudo-Mosco por la "pronta muerte» de Bion: « $A$ Ay! La malva cuando en el huerto muere, igual que el verde apio y que el florido y encrespado eneldo, tornan luego a la vida y nacen otro año más [...], mientras tú yacerás en silencio sepultado en la tierra ${ }^{60}$. Después, una vez resignado a la lamentatio de rigor, entendió que lo que el modelo cercano del Adonis representaba era en realidad un ciclo de muerte precoz y renovación constituido por las estaciones ${ }^{61}$. La idea de un joven hermoso cuya belleza se mantenía inmarcesible en los ciclos naturales debido a una muerte temprana proporcionó a Cernuda su más ansiada consolatio; de ahí que insistiera en la «gracia y tu juventud incomparables» de su amigo y que pudiera, finalmente, elevarlo a la esfera del "puro amor de un dios adolescente / entre el verdor de las rosas eternas».

La suerte de Adonis, comparada en el idilio XV teocritiano a la de Ganimedes, el hermoso adolescente que raptó Zeus ${ }^{62}$, y su extraordinaria belleza permanentemente joven han debido jugar un papel fundamental en la consideración del personaje como ejemplo de hermosura masculina, pura, y,

59. Luis Cernuda, Poesía completa, op. cit., pp. 354-355.

60. Canto fúnebre por Bion, vv. 100-102 y 106; en Bucólicos griegos, op. cit., pp. 308-309. Por las fechas de composición de la elegía a Lorca, Cernuda estaría en contacto con el tópico a través de la lectura de Giacomo Leopardi, quien escribió Il tramonto della luna, composición en la que se expresan tales ideas de renovación, fugacidad y muerte prematura. Escribía Cernuda en Historial de un libro: «La muerte trágica de Lorca no se apartaba de mi mente. En las noches de invierno de 1936 a 1937, oyendo el cańoneo en la ciudad universitaria, en Madrid, leía a Leopardi», en Luis Cernuda, Prosa I, op. cit., p. 643.

61. La más bella síntesis poética de esta idea está en Teócrito, Idilio V, vv. 135-136: «Sólo tú, caro Adonis, entre los semidioses, como es fama, vienes acá y vuelves al Aqueronte», en Bucólicos griegos, op. cit., p. 156. Resulta cuando menos llamativo que en su «Poética» para la famosa Antología de Gerardo Diego (1934) Cernuda reuniera en una misma visión a poetas como Shelley, Keats o Teócrito: «Recuerdo ahora, es verdad, la vida de Byron, la de Shelley, la de Keats. Y más lejos aún, en el mundo de lo que nunca fue, los pastores de Teócrito», en Luis Cernuda, Prosa II, op. cit., p. 64.

62. Teócrito, Idilio XV, vv. 123-124. Recuérdese para el mito de Ganimedes el poema «El águila» (1941), en Luis Cernuda, Poesía completa, op. cit., pp. 321-323. 
en consecuencia, de inevitable espíritu homosexual u homoerótico. Como era de esperar, Cernuda no desconocía esta concepción sobre la figura mitológica de Adonis. Es más: la alimentó y la vinculó a la imagen que tenía de Lorca, homosexual como él, no solo en la elegía que le dedicara a su muerte, sino también, años más tarde, en un texto escrito originariamente para Ocnos en el que reflexionaba sobre la homosexualidad bajo el título de «Epentismo y epénticos», términos creados, como es bien sabido, por el propio Lorca:

Recuerdo haber oído a F.G.L. exclamar, ante aquella tonta frasecita de J.R.J. equiparando la poesía con la mujer desnuda, «¿La mujer desnuda? ¡El hombre desnudo!» [...]. Y aun escogida una u otra forma del objeto sexual, todavía queda otra selección decisiva. Góngora (pues que nos apoyamos en referencias literarias) tiene un verso donde junta en una sola forma [dos objetos de deseo bien] imposible de reunir en uno solo. El amante celoso ve a la amada en brazos de un rival, pero la hermosura de éste es difícil de definir y precisar, pues la ve en brazos no sabe si "de un fiero Marte o de un Adonis bello". Aun ya terminada la preferencia sexual en el objeto de la misma, aún queda otra importante decisión, decisión que presupone la función que se espera de dicho objeto: así, unos irán fatalmente [encaminados] al fiero Marte y otros al Adonis bello ${ }^{63}$.

Símbolo de resurrección, paradigma de la belleza masculina, figura recurrente en el imaginario homosexual... y su muerte, desde los cantos fúnebres de Bion y el Pseudo-Mosco, hasta la elegía de Shelley, asociada de alguna forma a la muerte prematura del poeta. El personaje de Adonis debió ofrecérsele a Cernuda con todo su esplendor, atractivo y enorme depósito de significaciones literarias ante la desgarradora muerte de su amigo Lorca. En 1936, como hemos dicho, el sevillano se familiarizó con el mito gracias a la lectura del Adonais de Shelley, una obra en la que el tono personal y metafísico acaba superponiéndose, como en $A$ un poeta muerto (F.G.L.), a las formas propias de la elegía pastoral, aunque tal vez de un modo más notorio en el poema de Cernuda. Como indicábamos antes, de las principales convenciones de la modalidad bucólico-elegíaca, tan solo la apotheosis de Lorca se muestra inequívocamente dependiente de los modelos señalados, por lo que resulta forzoso, a priori, ubicar de lleno la elegía cernudiana en tales derroteros literarios. No es esta, hay que decirlo, intención nuestra en absoluto; pero, con todo, creemos que es acuciante patentizar ciertos vestigios clásicos del poema de Cernuda, tópicos reformulados, alusiones mitológicas que, aun escamoteadas, traen a la memoria no solo las costumbres de un género, sino también verdaderos hitos de la tradición occidental, como lo son, qué duda cabe, las figuras de Adonis u Orfeo.

Señalemos, ante todo, lo incontestable: nada más dar comienzo a su elegía, Cernuda recordó los tópicos de la mors inmatura y de la flor cortada, asociados en muchos casos, y ampliamente difundidos a través de todo tipo de poesías de carácter fúnebre, lo cual incluye, por supuesto, composiciones pastoriles ${ }^{64}$.

63. Luis Cernuda, Prosa II, op. cit., p. 782.

64. Recoge numerosos ejemplos el estupendo trabajo de Antonio Ramajo Caño, «Huellas clásicas en la poesía funeral española (en latín y romance) en los Siglos de Oro», Revista de Filología Española, vol. LXXIII, n. ${ }^{\circ} 3-4,1993$, pp. 313-328. 
Antes de citar los versos de la versión definitiva de la elegía, quizá convenga reproducir el germen de los mismos, presente en un folio manuscrito de la primera redacción:

Eras la flor de la vida y te aplastaron al aplastar la vida ${ }^{65}$.

El tópico, con alguna ligera variación (es más frecuente hallar la flor "cortada» que "aplastada»), está, por ejemplo, en la Égloga III de Garcilaso: «cuya vida mostraba que había sido / antes de tiempo y casi en flor cortada» (vv. 27-28). Mucho más sofisticada y con mayor alcance simbólico aparece la imagen en la Égloga II, fruto del diseño comparativo en el que Garcilaso la inserta:

Puso en el duro suelo la hermosa
cara, como la rosa matutina,
cuando ya el sol declina al mediodía,
que pierde su alegría y marchitando
va la color mudando; o en el campo
cual queda el lirio blanco que'l arado
crudamente cortado al pasar deja,
del cual aun no s'aleja presuroso
aquel color hermoso o se destierra

(vv. 1253-1261).

Cernuda, como anunciábamos arriba, reelaboró o modificó el tópico en la versión definitiva de la elegía, quizá dejando más vago su sentido original, pero añadiéndole otro más acorde con su particular lamentatio. Lo más curioso de todo es que, al rehacer la idea, siguió una estructura comparativa similar a la de Garcilaso, y más similar aún, por sus concomitancias, con otra de Diego Hurtado de Mendoza sobre la muerte de Adonis. Estos son, al fin, los primeros versos de "A un poeta muerto (F.G.L.)»:

Así como en la roca nunca vemos

la clara flor abrirse,

entre un pueblo hosco y duro

no brilla hermosamente

el fresco y alto ornato de la vida.

Por eso te mataron, porque eras

verdor en nuestra tierra árida

y azul en nuestro oscuro aire

(vv. 1-8).

Está claro que Cernuda ha echado mano para la construcción de la estrofa de imágenes procedentes de la tradición bucólica y elegíaca ${ }^{66}$. No obstante, ha

65. Derek Harris transcribió y publicó las primeras versiones de la elegía, anotando, además, un buen puñado de versos y estrofas variantes; véase, para este caso, El escritor y la crítica, op. cit., p. 298.

66. Véase, por ejemplo, Virgilio, Bucólica V, v. 34 («tu decus omne tuis»); y Bucólica VII, vv. 57-60 («Aret ager, uitio moriens sitit aëris herba, / Liber pampineas inuidit collibus umbras. / Phyllidis aduentu nostrae nemus omne uirebit»). 
habido en cierto modo una evidente variación de sentido: la flor que nunca se ve abierta o que no ha llegado a abrirse, no remite, como pudiera parecer y sería esperable, a la muerte en la flor de la juventud ${ }^{67}$, del mismo modo que la «tierra árida» y «el oscuro aire» tampoco aluden (aunque esté evocado) al impacto negativo en la naturaleza que provoca la ausencia o la muerte del pastor o poeta $^{68}$. En realidad, de lo que se trata es de aclarar que Lorca ha muerto precisamente por ser como una flor hermosa y viva en un mundo oscuro y yermo. Podríamos decir, en consecuencia, que Cernuda no ha buscado explicar en qué momento ha ocurrido la tragedia, el «cuándo» en que se basa el tópico de la mors inmatura (inevitablemente sugerido por la imagen de la flor que no se abre), sino el "porqué», la verdadera causa que explicaría la tragedia. Todo esto no impide, por supuesto, que Cernuda recordara en algún momento de la configuración de la primera estrofa de su elegía algunos elementos compositivos de la fábula de Adonis de Hurtado de Mendoza:

Tal lo halló cual flor de primavera que poco antes honraba el verde prado:

fresca, alta y en orden la primera; mas fue al pasar tocada del arado, cual blanco jazmín o adormidera cogido en un instante y arrojado; la tez y resplandor de hermosura vueltos en sombra eterna y noche escura.

(vv. $801-808)^{69}$.

Establecida ya la filiación del texto cernudiano con varias expresiones de la tradición bucólico-elegíaca, queda solamente poner al descubierto sus estrechas relaciones con la cultura grecolatina. El ejemplo más incuestionable que demuestra tales vinculaciones nos lo ofrece justamente la estrofa que fue censurada en la primera publicación de la elegía ${ }^{70}$ :

Aquí la primavera luce ahora.

Mira los radiantes mancebos

que vivo tanto amaste

67. La imagen de la florida juventud está en Virgilio, Bucólica VII, v. 4 («ambo florentes aetatibus»). Pero véase, no muy lejos de Cernuda, Milton, Lycidas, v. 8 («For Lycidas is dead, dead ere his prime»; en traducción de Madariaga: «Ha muerto Lycidas, ha muerto en flor», op. cit., p. 9); y sobre todo Shelley, Adonais, VI («The bloom, whose petals nipped before, they blew / died on the promise of the fruit, is waste; / the broken lily lies»).

68. Así en Virgilio, Bucólica V, vv. 35-39; podría haber, incluso, destellos en los versos de Cernuda de la Égloga I de Garcilaso: «la tierra, que de buena / gana nos producía / flores con que solía / quitar en sólo vellas mil enojos, / produce agora en cambio estos abrojos, / ya de rigor d'espinas intratable» (vv. 302-307).

69. Diego Hurtado de Mendoza, Poesía completa, ed. de José Ignacio Díez Fernández, Barcelona, Planeta, 1989, p. 126. Cernuda pudo leer la fábula de Adonis de Mendoza en Poetas líricos de los siglos XVI y XVI, ed. de Adolfo de Castro, B.A.E., XXXII, 1854, pp. 68-70. La referencia a la «adormidera» en el v. 805 pudo activar el recuerdo mitológico de los vv. 28-30 de la elegía cernudiana.

70. Sobre la censura de la estrofa habla, entre otros, José Teruel, en «Notas sobre un cuaderno autógrafo de Luis Cernuda, Ínsula. Revista de Letras y Ciencias Humanas, n. ${ }^{\circ} 669$, 2002, pp. 28-29. 
efímeros pasar juntos al fulgor del mar. Desnudos cuerpos bellos que se llevan tras de sí los deseos con su exquisita forma, y sólo encierran amargo zumo, que no alberga su espíritu un destello de amor ni de alto pensamiento.

(vv. 40-48).

Mucho podría decirse acerca de estos versos, pero ciñámonos mejor a nuestro propósito. La escena de los jóvenes bañistas exhibiendo sus cuerpos desnudos, frecuentísima en toda clase de representaciones artísticas y literarias de tema homoerótico y homosexual, está indiscutiblemente asociada al mundo griego y a los ideales de belleza masculina de la sociedad helena ${ }^{71}$. Cernuda, atento como pocos a la historia de las tradiciones, conocía muy bien el origen de la imagen, sus conexiones con el mundo antiguo y, sobre todo, con Arcadia. El propio Cernuda lo reconocía en 1941 en una breve nota sobre Gregorio Prieto:

$\mathrm{Al}$ obtener Prieto, muy joven aún, el premio de Roma, la larga estancia en Grecia e Italia había de revelarle un ideal que poco a poco iría convirtiéndose en obsesión, llegando en ocasiones casi a ahogar en él el instinto de lo real. Fruto de aquellos años eran las obras que expuso en Madrid hacia 1936. Este ideal, más que una añoranza del clasicismo pagano, es una añoranza de cierta imposible edad de oro, simbolizada en sus lienzos una y otra vez por hermosos cuerpos juveniles, desnudos y amorosos, que pueblan blancas ruinas del litoral mediterráneo ${ }^{72}$.

La cita es clara y habla por sí misma, y puede ponerse en relación con estas anotaciones del diario de Cernuda, escritas en el verano de 1934: «Hecha una foto a unos muchachos que se bañan desnudos. Quién fuera uno de estos golfillos gaditanos». Cuatro días después de inmortalizar esta visión, el sevillano deja constancia en su diario de cuál es su lectura en esas horas estivales: «Último día libre, hace unos años, en Málaga. Teócrito por la mañana, en el jardín» ${ }^{73}$. A la luz de estas revelaciones, una evidencia se impone: en el imaginario cernudiano, los jóvenes desnudos y el melancólico recuerdo del mundo arcádico no solo consituyen proyecciones indisociables, sino también materia que es capaz de propiciar el más sentido canto elegíaco. Al componer Cernuda su elegía entre finales de 1936 y principios de 1937, la imagen erótica de los muchachos desnudos tuvo que ofrecérsele casi como una tentación necesaria. Tanto por la intensidad de su paganismo como por su evidente evocación de lo bucólico-elegíaco la escena de los muchachos desnudos satisfacía de todo punto el propósito literario del poeta: situar su elegía en una tradición de raigambre absolutamente clásica, a caballo entre el idilio pastoril y la elegía de carácter funerario ${ }^{74}$.

71. Quizá uno de los tesimonios literarios más antiguos se encuentre en Homero, Ilíada, X, 570-576.

72. Luis Cernuda, Prosa II, op. cit., pp. 176.

73. Luis Cernuda, Prosa II, op. cit., p. 759.

74. Cabe preguntarse cuánto pudo sugestionarle a Cernuda la lectura de este fragmento amatorio de la Elegía I de Garcilaso, donde se describen los sufrimientos de Venus ante la 
Pongamos fin a estas líneas sobre la presencia grecolatina en «A un poeta muerto (F.G.L.)» desvelando, como no podía ser de otra manera, la de la figura de Orfeo, correlato mitológico del poeta cantor, y difusor, como se sabe desde Ovidio, «de la práctica de trasladar el amor a los muchachos aún tiernos y de arrancarles la breve primavera de su edad y la primera flor antes de la juventud ${ }^{75}$. En dos momentos de su elegía Cernuda permite que se oigan los ecos del músico de Tracia. El primero de ellos trae el recuerdo de la muerte de Orfeo a manos de las bacantes, eternas despechadas porque el músico no quiso corresponder a su amor. Estas, desde la cima de una colina, divisaron al músico entonando su hipnótico canto, a lo que respondieron lanzándole piedras y demás proyectiles que, fatalmente, acabaron con su vida:

Carmine dum tali siluas animosque ferarum
Threicius uates et saxa sequentia ducit,
ecce nurus Ciconum tectae lymphata ferinis
pectora uelleribus tumuli de uertice cernunt
Orphea percussis sociantem carmina neruis.
e quibus una leues iactato crine per auras
'en' ait, 'en, hic est nostri contemptor!' et hastam
uatis Apollinei uocalia misit in ora,
quae foliis praesuta notam sine uulnere fecit;
alterius telum lapis est, qui missus in ipso
aere concentu uictus uocisque lyraeque est,
ac ueluti supplex pro tam furialibus ausis
ante pedes iacuit. sed enim temeraria crescunt
bella, modusque abiit, insanaque regnat Erinys.
cunctaque tela forent cantu mollita, sed ingens
clamor et infracto Berecynthia tibia cornu
tympanaque et plausus et Bacchei ululatus
obstrepuere sono citharae. tum denique saxa
non exauditi rubuerunt sanguine uatis

(vv. 1-19) ${ }^{76}$.

muerte de su amante Adonis, y que tanto criticó Herrera por parecerle demasiado lascivo para ocasiones de tristeza: «Y luego con gracioso movimiento / se fue su paso por el verde suelo, / con su guirnalda usada y su ornamento; / desordenaba con lascivo vuelo / el viento su cabello; y con su vista / s'alegraba la tierra, el mar y el cielo» (vv. 235-240). Conviene fijarse, además, en un tópico presente en la estrofa cernudiana muy frecuente en la elegía clásica de temática amorosa: la consideración de lo amado como cosa agridulce. Aquel dulce malum del que hablaba Ovidio (Amores, II, 9, 26-27) se encuentra en el maravilloso oxímoron «amargo zumo» (v. 47). La idea tuvo que llegarle a Cernuda por varios lugares; no obstante, es posible que por aquellas fechas la leyera en la Antología griega, concretamente en Meleagro, quien menciona, también, la célebre imagen del «aguijón» que encontramos en Cernuda (v. 54): «Est-ce que veux nous rappeler qu'elle porte, elle aussi, à la fois doux et toujours piquant au coeur, l'aiguillon d'Éros aux flèches cruelles?» (A. P. V, 163), Anthologie grecque, tomo II (Libro V), París, Les Belles Lettres, 1928 p. 76.

75. Ovidio, Metamorfosis, X, 83-86; hemos seguido aquí la traducción de José Carlos Fernández Corte y Josefa Cantó Llorca, en Ovidio, Metamorfosis (Libros VI-X), Madrid, Gredos, 2012, p. 172.

76. Citamos por la monumental edición de Samuel Díez Reboso, base de su tesis doctoral Edición critica y comentario textual del libro XI de las Metamorfosis de Ovidio, Universidad de Huelva, 2012, pp. 1-8. 
Cernuda recordó este episodio de odio hacia el Orfeo homosexual ovidiano ${ }^{77}$ al lamentar la incomprensión y el rechazo de los españoles hacia el «cantor» (v. 75), hacia «aquel que ilumina las palabras opacas / por el oculto fuego originario» (v. 21-22):

\author{
El odio y la destrucción perduran siempre \\ sordamente en la entrańa \\ toda hiel sempiterna del español terrible, \\ que acecha lo cimero \\ con su piedra en la mano. \\ Triste sino nacer \\ con algún don ilustre \\ aquí, donde los hombres \\ en su miseria sólo saben \\ el insulto, la mofa, el recelo profundo
}

(vv. 11-20)

La alusión a la muerte de Orfeo es casi inapreciable, pues los únicos elementos textuales que conectan los versos de la elegía a los de Ovidio son los que hacen referencia a las piedras como armas y a la imagen de la cima. No obstante, la presencia del músico de Tracia queda corroborarada gracias a la estrofa siguiente, la más explícitamente inspirada en la literatura grecolatina que se deja ver en el poema cernudiano:

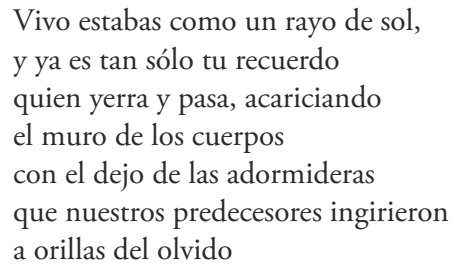

(vv. 24-30).

77. Para la presencia de Orfeo en Cernuda son imprescindibles los estudios de Bienvenido Morros, «El Orfeo homosexual en "Los placeres prohibidos", de Luis Cernuda», en Crítica hispánica, vol. 35, n. ${ }^{\circ}$ 2, 2013, pp. 87-102; y "La muerte de Orfeo en un poema de "Los placeres prohibidos" de Luis Cernuda», en Minerva. Revista de Filología Clásica, n. ${ }^{\circ}$ 27, 2014, pp. 239-269. 
El camino hacia la trascendencia del poeta muerto ha de pasar necesariamente por el olvido de la vida terrena mediante el efecto de las adormideras. Para su formulación en el plano poético, Cernuda ha tenido en mente el destino de Orfeo, su camino hacia la trascedencia según lo cuenta Virgilio: «post, ubi nona suos Aurora ostenderit ortus, / inferias Orphei Lethaea papauera mittes" ${ }^{78}$.

Poetas tan fundamentales para la tradición bucólico-elegíaca como el Pseudo-Mosco o, muchos siglos más tarde, Milton, también se acordaron de la figura de $\mathrm{Orfeo}^{79}$. Y nunca fue una evocación infundada: al fin y al cabo, cantaban a la memoria y resurrección de un poeta muerto.

78. Virgilio, Georgicas, IV, vv. 544-545. Una traducción que pudo conocer Cernuda sería

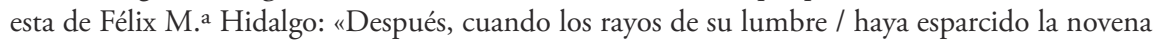
Aurora, / por funeral tributo adormideras / en el agua bańadas del Leteo / a la sombra de Orfeo / ofrece», en Virgilio, Églogas y Geórgicas, Madrid, a cargo de Víctor Saiz, 1879, p. 209.

79. Pseudo-Mosco, Canto fúnebre por Bion, vv. 115-127; Milton, Lycidas, vv. 58-63. 
